\title{
Concepções e discursos sobre a docência: tensões, embates e perspectivas
}

\author{
Edileuza Fernandes Silva ${ }^{1}$ \\ André Lúcio Bento ${ }^{2}$
}

\begin{abstract}
RESUMO
Analisam-se concepções acerca da docência expressas na Resolução $\mathrm{n}^{0} 2$, de $1^{\circ}$ de julho de 2015 , na Portaria ${ }^{\circ} 38$, de 28 de fevereiro de 2018 e em narrativas de três professores de cursos de licenciatura de uma instituição de ensino superior pública da região Centro-Oeste. A discussão é parte de estudo qualitativo em desenvolvimento sobre a formação didático-pedagógica de professores para a Educação Básica, cujos dados foram obtidos de documentos e entrevistas narrativas. As análises preliminares indicam que os documentos apresentam discursos e concepções de docência, articulados aos contextos social, político, econômico e educacional de sua elaboração. Os docentes que formam professores, compreendem a docência relacional como processo de trabalho coletivo, influenciada pelas experiências pessoais e acadêmicas. Há ainda a identificação da docência como sacerdócio e orientada pela pesquisa, expressando uma ambiguidade conceitual.
\end{abstract}

PALAVRAS-CHAVE: Formação docente. Educação. Políticas.

Conceptions and discourses about teaching: tensions, conflicts and perspectives

\section{ABSTRACT}

An analysis of the concepts on the teaching expressed in Resolution no. 2 of July 1, 2015, Order no. 38 of February 28, 2018 and the narratives of

\footnotetext{
1 Doutora em Educação. Faculdade de Educação da Universidade de Brasília. Brasília-DF. Brasil. http://orcid.org/0000-0002-9837-2958. E-mail: edileuzafeunb@gmail.com

2 Doutor em Linguística. Subsecretaria de Formação Continuada dos Profissionais da Educação da Secretaria de Estado de Educação do Distrito Federal. Brasília-DF. Brasil. https://orcid.org/0000-0001-6404-3841. E-mail: andreluciobento@gmail.com
} 
three university teachers of a public institution of higher education in the Center region West. The discussion is part of a qualitative study in the development of the didactic-pedagogical formation of teachers for basic education, how much information was obtained from documents and narrative interviews. The preliminary analyzes indicate that the documents present speeches and conceptions of the teaching, articulated to the social, political, economic and educational contexts of their elaboration. Teachers who are teachers understand relational teaching as a process of collective work, influenced by personal and academic experiences. There is also the identification of the teaching as priesthood and guided by the investigation, that expresses a conceptual ambiguity.

KEYWORDS: Teacher training. Education. Policies.

Concepciones y discursos sobre la enseñanza: tensiones, enfrentamientos y perspectivas

\section{RESUMEN}

Se analizan los conceptos sobre la enseñanza expresados en la Resolución $\mathrm{n}^{\circ} 2$ del 1 de julio de 2015, la Ordenanza n ${ }^{\circ} 38$ del 28 de febrero de 2018 y las narraciones de tres docentes universitarios de una institución pública de educación superior de la región Centro Oeste. La discusión es parte de un estudio cualitativo en desarrollo sobre la formación didácticopedagógica de docentes para educación básica, cuyos datos se obtuvieron de documentos y entrevistas narrativas. Los análisis preliminares indican que los documentos presentan discursos y concepciones de la enseñanza, articulados a los contextos sociales, políticos, económicos y educativos de su elaboración. Los maestros que forman maestros entienden la enseñanza relacional como un proceso de trabajo colectivo, influenciado por experiencias personales y académicas. También existe la identificación de la enseñanza como sacerdocio y guiada por la investigación, que expresa una ambigüedad conceptual.

PALABRAS CLAVE: Educación. Formación. Enseñanza. Profesor. Políticas

$$
* * *
$$




\section{Introdução}

As transformações ocorridas na economia e na produção, a partir da década de 1990, decorrentes da crise estrutural do sistema capitalista, caracterizadas pela flexibilização do trabalho (ANTUNES; PINTO, 2017), desenham o cenário político e cultural que influenciaram políticas educacionais no Brasil e demandaram a formação de profissionais competentes e com capacidades cognitivas flexíveis para 'saber fazer'. A expectativa era de que essa formação desenvolvesse habilidades e competências que possibilitassem ao trabalhador resolver problemas postos pela prática cotidiana de maneira rápida e eficiente, adaptando-se ao processo produtivo em constante mudança.

Em relação à formação de professores que, até a década de 1990 era fundamentada na razão técnico-instrumental com ênfase no desenvolvimento da capacidade de resolver problemas práticos por meio da aplicação de teorias e instrumentos técnicos, passa-se à defesa da dimensão prática do trabalho docente, com o argumento de que o contato do futuro professor com a escola desde o início do curso possibilitaria o desenvolvimento de habilidades cognitivas e práticas para atender à complexidade social e às demandas educativas (CURADO SILVA e LIMONTA, 2014).

Com as mudanças que ocorreram na gestão da educação nacional a partir de 2016 com o impeachment da presidente Dilma Rousseff, retoma-se “com força a orientação técnico-instrumental para a formação dos professores, configurada numa racionalidade sistêmica sustentada pelo aporte das competências" (ANPED, 2019), em contraposição ao que defende o movimento dos educadores e de suas entidades representativas - uma sólida formação teórica para os professores. Sob essa orientação, são elaborados os documentos que passam a normatizar a formação do futuro professor. Os discursos propalados são de uma formação 'praticista' em que "a prioridade absoluta corresponde à prática, e tanto mais corresponderá 
quanto menos impregnada estiver de ingredientes teóricos" (SÁNCHEZ VÁZQUEZ, 2007, p. 240), reforçando-se a dicotomia entre teoria e prática e comprometendo a formação crítica e emancipadora do professor.

Diante dos questionamentos suscitados por essas mudanças de perspectivas formativas, este artigo objetiva refletir sobre os discursos de docência predominantes na Resolução $\mathrm{n}^{0} 2$, de $1^{0}$ de julho de $2015^{3}$, que define as Diretrizes Curriculares Nacionais para a formação inicial em nível superior (cursos de licenciatura, cursos de formação pedagógica para graduados e cursos de segunda licenciatura) e para a formação continuada (BRASIL, 2015)4, e na Portaria $\mathrm{n}^{0}$ 38, de 28 de fevereiro de 2018, da Coordenação de Aperfeiçoamento de Pessoal de Nível Superior (MEC/CAPES, 2018) ${ }^{5}$ que institui o Programa de Residência Pedagógica (PRP), uma das ações que compõem a Política Nacional de Formação de Professores (BRASIL, 2017).

Propõe-se a reflexão sobre o que esses documentos que apresentam orientações atuais voltadas à formação docente revelam acerca da docência e do ser docente. Embora formulados e aprovados em contextos históricos distintos sob orientações políticas, ideológicas e econômicas diferentes, estão na agenda do debate da formação de professores. A Resolução 2/2015 tem sido constantemente ameaçada no momento que deveria ser o de implementação de seus princípios e fundamentos nos projetos pedagógicos de cursos das instituições de ensino superior.

Serão também discutidas concepções de três professores de cursos de graduação em Licenciatura (Pedagogia, Educação Física e História) de uma instituição de ensino superior pública (IES), a partir de dados levantados por meio de entrevistas narrativas, que compõem estudo em desenvolvimento sobre a formação didático-pedagógica de professores para a

\footnotetext{
${ }^{3}$ Em 20 de dezembro de 2019, o Conselho Nacional de Educação (CNE) aprovou a Resolução CNE/CB 02, que define as novas Diretrizes Curriculares Nacionais para a Formação Inicial de Professores para a Educação Básica e institui a Base Nacional Comum para a Formação Inicial de Professores da Educação Básica (BNC-Formação). As instituições formadoras terão um período de até 3 (três) anos para adequação de seus projetos e currículos

${ }^{4}$ A partir desse momento será identificada como DCN/2015.

${ }^{5}$ A partir desse momento será identificada como PRP/2018.
} 
Educação Básica. As entrevistas narrativas possibilitaram reconstruir pensamentos, representações e elementos do sistema simbólico dos professores (BAUER et al., apud SHÜTZE, 1974) e produziram um significativo material para discutir a docência por eles concebida em relação à docência assumida nos documentos.

A discussão assenta-se no pressuposto de que os discursos sobre docência presentes nas DCN/2015 e no PRP/2018 visam responder a demandas e desafios momentâneos de grupos no poder. Isso porque, no contexto de influência das políticas, busca-se contemplar grupos de interesses organizados para formular as políticas e legitimar os discursos para sua sustentação e construir uma agenda política que passa a se constituir como senso comum nacional, embora seja o desejo de um governo, em um dado momento, em uma dada circunstância da vida política do País (BALL, 2006).

Muitas vezes, essas políticas de governo são propostas para atender a ocorrências conjunturais e a interesses expressos por fundamentos econômicos, políticos, ideológicos ou religiosos, demandados por setores da sociedade, sem ligação direta com a área da educação, podendo impactar na formação, no trabalho do professor e representar obstáculos à profissionalidade docente que, conforme Curado Silva (2008), se refere ao exercício da docência com competência técnica, compromisso ético e político com o trabalho. A profissionalidade dispõe, ainda, sobre "o conjunto do grupo profissional dos professores num dado momento histórico" (SARMENTO 1998 apud BRZEZINSKI, 2002, p. 10), tendo portanto, forte sentido político e pedagógico.

A partir dessas reflexões iniciais, serão feitos alguns cotejamentos entre os documentos citados e as narrativas dos professores, admitindo-se que sugerem discursos atribuídos à docência que transitam da visão conservadora à transformadora, ora com o predomínio de uma, ora de outra, influenciando as políticas de formação docente, a construção de uma imagem do professor e as perspectivas de formação assumidas nas IES. O discurso, 
conforme Fairclough (2001, 2003), é um dos momentos das práticas sociais, elemento que contribui para a construção de sistemas de crenças e de valores, inclusive políticos, morais e éticos.

Assim, ao mesmo tempo em que se reafirma a necessidade de mudanças curriculares, de política de formação e de condições de trabalho docente, carreira e salário, acredita-se que os discursos assumidos em documentos oficiais nacionais, que orientam políticas públicas de formação docente no atual cenário educacional, ensejam compreensões amplas e diversas de docência, movidas por interesses políticos e econômicos que repercutem nas representações que a sociedade constrói sobre a docência e sobre o trabalho do professor.

\section{Docência: uma construção complexa}

A palavra 'docência' tem registro na língua portuguesa em 1916 (INFOPÉDIA, 2003-2008). Embora o uso do termo nos discursos do campo educacional seja relativamente recente, os sentidos a ele atribuídos ao longo do tempo são influenciados pelo momento histórico e pelos interesses políticos e ideológicos dominantes, e interferem na elaboração e implementação de políticas de formação de professores no Brasil. Conforme Saviani (2011, p. 9), essa formação tem sido orientada pelo 'modelo de conteúdos culturais-cognitivos', que pressupõe o domínio da cultura geral e de conteúdos específicos da área de conhecimento na qual o docente irá atuar, bem como, de acordo com o 'modelo pedagógico-didático', que reserva à formação pedagógica e didática a completude da formação de docentes para a Educação Básica. A ênfase recai ora sobre um modelo, ora sobre outro. No entanto, estudos recentes (SILVA, 2018; SILVA e CRUZ, 2017) refletem sobre a epistemologia da práxis como perspectiva crítica e emancipadora que reconhece na unidade teoria-prática dimensão estruturante da atividade docente e que influencia os processos didático- 
pedagógicos e a compreensão dos professores sobre o conhecimento que ensinam.

Para Veiga (2009, p. 24), a "docência é o trabalho dos professores; na realidade, estes desempenham um conjunto de funções que ultrapassam a tarefa de ministrar aulas" que incluem gestão, coordenação do trabalho pedagógico, supervisão, entre outras. Essas ações são produzidas nas relações e nas ações dos atores sociais - os docentes com os estudantes, os docentes com seus pares - em um processo dialógico e dialético. A docência é tecida na e pelas relações humanas, o que a caracteriza como ação de natureza essencialmente humana.

Como atividade humana, objetiva e transformadora a docência requer formação específica na área de conhecimento pleiteada pelo licenciando e formação didático-pedagógica contemplada na organização curricular dos cursos de formação de professores, o que significa "pensar a formação para a docência numa perspectiva larga" (FARIAS, 2019, p. 163), reconhecendo a complexidade de ensinar, de ser professor, a diversidade dos contextos de trabalho e a pluralidade social e cultural dos estudantes.

A docência é uma atividade complexa, tendo em vista as dificuldades envolvidas no 'ser professor' para além de estar professor. 'Estar professor' pressupõe o domínio de conhecimentos e habilidades que possibilitem realizar um trabalho como meio de garantir a sobrevivência na ausência de outra atividade profissional (ZABALZA, 2017). A opção de muitos estudantes pela licenciatura parece estar sendo feita com essa expectativa, mesmo assim, entre 2006 e 2015 "a taxa de adolescentes brasileiros de 15 anos que almejam seguir a carreira docente caiu de cerca de $7,5 \%$ para apenas 2,4\%", revelam dados do relatório da Organização para a Cooperação e Desenvolvimento Econômico (OCDE) divulgado em junho de 20196 .

Por outro lado, 'ser professor' não é apenas exercer um ofício, mas o exercício responsável da docência, (Idem, p. 19) com compromisso político

\footnotetext{
6 "Cai número de jovens que querem ser professores, diz relatório da OCDE". Disponível em: https://www.revistaeducacao.com.br/cai-numero-de-jovens-que-querem-ser-professores-diz-relatorio-da-ocde/. Acesso em: 06 out. 2019.
} 
com a transformação da realidade individual e coletiva e de consciência de sua condição de membro de uma categoria profissional.

A docência precisa ser compreendida nas múltiplas dimensões que a influenciam: pessoal, profissional e de trabalho. Na dimensão pessoal, são consideradas as experiências de uma trajetória de vida, as condições de vida dos professores, a imagem que eles têm de si e que reflete a imagem construída social e historicamente. O imaginário social sobre o docente é também construído com base em documentos e orientações oficiais sobre a formação de professores, pois esses expressam modelos que sugerem determinadas compreensões de professor: técnico, prático ou agente social de mudanças (VEIGA, 2002). Por isso, o questionamento ou reconstrução das percepções sobre o ser professor demanda tempo e revisão entre a forma como o professor se percebe e como é visto pela sociedade (ARROYO, 2000).

A dimensão profissional "é aquela em que se presta maior atenção, posto que constitui a essência do que um docente é e sabe fazer" (ZABALZA, 2017, p. 24), ou seja, o exercício profissional como possibilidade de fortalecer a identidade profissional,
unitária, alicerçada na articulação entre formação inicial e continuada e exercício profissional, regulado por um estatuto social e econômico, tendo como fundamento a relação: teoria e prática, ensino e pesquisa, conteúdo específico e conteúdo pedagógico, de modo a atender à natureza e à especificidade do trabalho pedagógico (VEIGA, 1998, p. 76-77).

Na dimensão profissional há de se considerar também a relevância da mobilização da categoria profissional docente para a conquista de uma identidade profissional que corrobora a profissionalidade. Entretanto, não se pode ignorar elementos desprofissionalizantes como: a precária situação de muitos professores com baixos salários, a ausência de carreira estruturada por instrumentos legais, a perda da autonomia, a formação inicial deficitária e o acréscimo de atividades de natureza administrativa, que muitas vezes 
exigem dos docentes uma dedicação que os distancia da atuação pedagógica voltada ao processo de ensino-aprendizagem. Nesse último caso, ocorrem, especificamente, duas transformações que a racionalização introduz em seu trabalho: "o reforço da função disciplinar do docente; e a transformação das tarefas de ensino-aprendizagem propriamente ditas, especialmente a de dotá-las de um caráter 'quantitativo' obriga que o professor adquira novas técnicas" (JÁEN, 1991, p. 79), para atender às demandas externas e de políticas educacionais. Dessa forma, as condições de trabalho docente constituem a terceira dimensão a ser considerada no conjunto dos fatores que impactam a docência e a profissionalidade.

A partir dessas dimensões entende-se a docência como atividade objetiva transformadora que tem um sentido individual, mas é construída coletivamente na relação que os docentes estabelecem com os estudantes, com seus pares e com a própria instituição. É, portanto, coletiva, relacional e indissociável das transformações sociais, do contexto e de suas determinações e requer a formação de professores na perspectiva críticoemancipadora, de modo a articular trabalho, relação teórico-prática e pesquisa (CURADO SILVA e LIMONTA, 2014).

Não se pode perder de vista em relação à docência, que os conhecimentos e as experiências são construções que acontecem em processos contínuos de mudança, inclusive das teorias, das ideias e do trabalho pedagógico, pensados e repensados no contexto histórico-social, sejam eles defendidos pelos educadores e pelas suas entidades representativas, sejam, como enuncia Ball (2006), defendidos por grupos de interesses das políticas.

\section{A docência à luz das Diretrizes Curriculares Nacionais de 2015}

Diretrizes "são orientações para o pensamento e a ação" (CIAVATTA e RAMOS, 2012, p. 11). Entendê-las é fundamental para apreender as 
perspectivas teóricas e metodológicas que orientam a formação de professores e revelam de maneira explícita ou implícita um modelo de professor (GARCIA, 1999) e de docência. Nas Diretrizes de 2015 a docência é ação educativa e como processo pedagógico intencional e metódico, envolvendo conhecimentos específicos, interdisciplinares e pedagógicos, conceitos, princípios e objetivos da formação que se desenvolvem na construção e apropriação dos valores éticos, linguísticos, estéticos e políticos do conhecimento inerentes à sólida formação científica e cultural do ensinar/aprender, à socialização e construção de conhecimentos e sua inovação, em diálogo constante entre diferentes visões de mundo (BRASIL, 2015, p. 3).

Como 'ação' a docência pode sugerir visão técnica e pragmática com ênfase no 'fazer', no 'aprender a fazer', de orientação técnico-instrumental, predominante na formação de professores no século XX. Quando a ação é privilegiada, temos, do ponto de vista ideológico, conforme enuncia Thompson (1995), a docência como modo de operação da 'dissimulação', por meio da estratégia para tornar opaca a realidade, quando se privilegia, metonimicamente, a parte e não o todo, a teoria ou a prática.

Entretanto, na perspectiva de práxis pedagógica, destaca-se a unidade indissolúvel entre teoria e prática, da autonomia e dependência de uma com relação à outra (SÁNCHEZ VÁZQUEZ, 2007). No art. $3^{\circ}$, parágrafo $5^{0}$ das DCN/2015, ao se destacar a articulação teoria-prática como princípio da formação de professores para a Educação Básica, que deve ocorrer em um processo de indissociabilidade entre ensino, pesquisa e extensão, busca-se reforçar a ação educativa no sentido de práxis de caráter intencional, que considera o conhecimento como produção histórica, situada na relação teoria-prática. Na constituição de práxis, a teoria tem uma função prática ao permitir a concepção de um processo futuro, caracterizando a perspectiva de formação de professores crítico-emancipadora que: 
busca construir a indissociabilidade da teoria e a prática na práxis - atividade humana que transforma o mundo natural e social para fazer dele o mundo humano, sem que essa atividade seja concebida com o caráter estritamente utilitário (CURADO e LIMONTA, 2014, p. 19).

Nesse enfoque, as DCN/2015 orientam para a necessidade de se contemplar, nos projetos pedagógicos dos cursos de licenciatura, a prática como componente curricular, articulada aos conhecimentos específicos e pedagógicos, e, ao mesmo tempo, para a articulação entre o currículo de formação inicial e o currículo da Educação Básica, aproximando a formação que ocorre nas IES dos espaços escolares, considerados também formativos. Assim, a prática como componente curricular deve ser entendida como atividade consciente e intencional, engendrada desde o início do processo formativo, articulada ao estágio supervisionado, sem se confundir com ele e que contribui para a formação do futuro professor.

As DCN/2015 expressam que a atividade docente não se sustenta em um conjunto de ações desarticuladas e justapostas, restritas ao observável, pois devem favorecer a "construção de conhecimentos e sua inovação, em diálogo constante entre diferentes visões de mundo" (BRASIL, 2015, p. 3). Dessa forma, destaca-se o caráter 'intencional' e 'metódico' da docência, que requer consciência, concepção, definição de objetivos, reflexão acerca das ações desenvolvidas, estudo e análise pelos docentes da realidade para a qual se pensa a ação educativa.

Essa perspectiva remete à docência como trabalho que produz conceitos, valores, ideias com finalidades vinculadas à concepção de homem/mulher que se deseja formar e de sociedade que se deseja construir. Trata-se da "produção do saber sobre a cultura, isto é, o conjunto da produção humana" (SAVIANI, 1991, p. 20) e que ocorre em processos didático-pedagógicos, contínuos e regulares, críticos e reflexivos com vistas ao alcance de objetivos e finalidades voltados à formação humana, 
acadêmica e profissional dos estudantes em uma perspectiva críticoemancipadora.

A docência como práxis pedagógica contempla a dimensão pessoal e profissional, discutida anteriormente, e conduz ao entendimento de que, por meio do trabalho docente, o professor transforma a si próprio e aos outros. Essa transformação é vista como finalidade da atividade prática; "sem essa ação real, objetiva sobre a realidade, que existe independentemente do sujeito prático, não se pode falar propriamente de práxis como atividade material consciente e objetivante” (SÁNCHEZ VÁZQUEZ, 2007, p. 194).

Assim, as DCN/2015 avançam na compreensão da docência e no reconhecimento de que formar docentes passa, necessariamente, pela construção de conhecimentos como elementos constitutivos da formação inicial e continuada em processos de articulação teoria-prática e ensinopesquisa-extensão, corroborando uma formação que oportuniza a construção pelo futuro professor da consciência sobre o seu papel transformador.

\section{A docência na perspectiva da Portaria n. 38 - Residência Pedagógica}

Dados do Censo Escolar de $2018^{7}$ evidenciam que, embora tenha ocorrido um crescimento na taxa líquida de matrículas nos últimos anos a garantia da qualidade da formação dos estudantes da Educação Básica ainda é um desafio para governos, escolas e instituições de ensino que formam professores. É consenso que o trabalho docente é um dos elementos para se conquistar a qualidade, no entanto, não é o único. Mesmo assim, tem sido recorrente por parte dos governos a responsabilização dos docentes e a sua desqualificação, a partir da vinculação da qualidade de sua atuação aos problemas que impedem a melhora da aprendizagem dos estudantes (FARIAS, 2019).

\footnotetext{
${ }^{7}$ Censo Escolar. http://portal.inep.gov.br/censo-escolar. Acesso em: 12 de out. 2019.
} 
Ao mesmo tempo, são recorrentes as manifestações de estudantes e formadores das IES de que o estágio obrigatório não tem cumprido a finalidade de aproximar os licenciandos da realidade da escola básica, de compreender a sua totalidade, de superar o seccionamento entre o mundo objetivo da escola e da sala de aula e o mundo subjetivo. Isso seria possível a partir de um processo formativo de reciprocidade dialética, na perspectiva da práxis como "atividade material consciente e objetivante" (SÁNCHEZ VÁZQUEZ, 2007, p. 194) que oportunizasse a compreensão da realidade da escola em toda a sua complexidade e do trabalho do professor como possibilidade de intervenção didático-pedagógica a partir da compreensão contextualizada e problematizadora dos questões que emergem dessa realidade.

O PRP/2018 é parte da Política Nacional de Formação de Professores (BRASIL, 2017) que, inspirado no modelo de residência médica8 ${ }^{8}$ regulamenta a residência em escolas públicas de Educação Básica (escolascampo) para que o licenciando realize atividades sob a orientação de um professor, como parte da formação inicial (BRASIL, 2018). A expectativa dos formuladores da política, expressa na Portaria n. 38/2018, é de que a Residência Pedagógica contribua para a formação de professores com competências e habilidades profissionais que favoreçam a realização de um trabalho qualitativamente satisfatório. Esse discurso ignora a relação direta entre melhoria da qualidade e financiamento da educação pública, e é falacioso diante da Emenda Constitucional n. 95/2016 que congela por vinte anos os gastos públicos nos valores de 2016 e das políticas de cortes na Educação Superior que afetam as licenciaturas. Como garantir qualidade sem investimentos em condições de trabalho e valorização dos professores?

O discurso oculta os dilemas da formação no Brasil e responsabiliza os docentes pelos graves problemas da educação escolar. Saviani (2011, p. 17), ao discutir esses dilemas, adverte para o fato de que

\footnotetext{
${ }^{8}$ No Brasil, o primeiro programa de residência médica foi criado em 1945 no Serviço de Ortopedia do Hospital das Clínicas da Faculdade de Medicina da USP. Disponível em: https://blog.imedicina.com.br/a-historia-da-residenciamedica/. Acesso em: 05 out. 2019.
} 
as condições de trabalho docente das escolas, a que se destinam os professores em formação, também influenciam na própria formação na medida em que o processo formativo implica o aspecto prático que tem como referência a rede escolar onde os estágios devem ser realizados. Ora, se o funcionamento das escolas é precário, os estágios também serão precários e, no limite, podem até mesmo ser inviabilizados ou reduzidos a procedimentos meramente formais.

A inserção de licenciandos em escola-campo cujas condições físicas e materiais são inapropriadas para a vivência de processos formativos pode exercer o efeito de precarizar a docência ainda no processo de formação inicial. A ênfase discursiva na formação como panaceia dos problemas educativos, do ponto de vista ideológico, é um modo de operação da dissimulação (quando relações de dominação tentam ser ocultadas ou negadas) (THOMPSON, 1995) levada a efeito por meio da estratégia de 'eufemização', ou seja, para abrandar a relação intrínseca entre condições de trabalho e qualidade do trabalho docente.

O PRP enfatiza o "fortalecimento do campo da prática" (BRASIL, 2018, p. 1), recuperando a concepção de docência e de formação hegemônica nas políticas de formação de professores no Brasil, especialmente a partir da década de 1990. Isso ocorre porque a ênfase na prática caracteriza "um exercício prático, que deve ser baseado na experiência, na atividade prática, o que, aparentemente, é considerado o eixo da formação docente" (CORDEIRO SILVA e LIMONTA, 2014, p. 11) proposta pelo PRP. Essa racionalidade prática, respalda-se na formação neotecnicista, que destaca o domínio de conteúdos curriculares da Educação Básica e a resolução de problemas imediatos postos pela prática.

Assim, a alternativa apresentada no PRP para promover a relação entre a teoria e a prática sugere a concepção de docência pragmática e de professor como um técnico que busca a racionalização dos processos de trabalho visando resultados aferidos por exames externos. Essa é uma 
perspectiva contrária à formação crítico-emancipadora que prima pela indissociabilidade da teoria e prática na práxis pedagógica, atividade humana objetiva e transformadora da realidade e pela autonomia dos professores para acompanhar e avaliar os processos de seu trabalho.

Paradoxalmente, a proposição de que a formação dos licenciandos ocorra em um processo de articulação "entre teoria e prática profissional docente, utilizando coleta de dados e diagnóstico sobre o ensino e a aprendizagem escolar, entre outras didáticas e metodologias" (BRASIL, 2018, p. 1) converge com o discurso das DCN/2015. É preciso, entretanto, considerar o movimento real, o contexto político e educacional em que as políticas são pensadas, bem como suas influências (BALL, 2006). Isso porque a formação de professores é um campo de disputa, são muitos os embates a serem pensados institucional e politicamente. Desse modo, as políticas públicas pensadas para a formação de professores não podem ocorrer num ritmo aligeirado, desconsiderando a efetiva participação dos diversos setores da educação como tem ocorrido com as políticas de formação docente, incluindo o Programa de Residência Pedagógica.

A divulgação do Programa em 2018 foi acompanhada de $\operatorname{críticas}^{9}$ da Associação Nacional de Pós-Graduação em Educação (ANPED), da Associação Nacional pela Formação dos Profissionais da Educação (ANFOPE), da Associação Nacional de Política e Administração da Educação (ANPAE), entre outras entidades e associações. A principal crítica recai sobre a submissão dos programas de formação inicial nos cursos de licenciatura à nova Base Nacional Comum Curricular, conforme um de seus objetivos apresentados no artigo $2^{\circ}$, inciso IV: "promover a adequação dos currículos e propostas pedagógicas dos cursos de formação inicial de professor da educação básica às orientações da BNCC".

Em outro posicionamento da ANPED sobre o "Texto referência Diretrizes Curriculares Nacionais e Base Nacional Comum para a formação

\footnotetext{
${ }^{9}$ Entidades se posicionam contrárias à padronização e controle impostos pelo Programa de Residência Pedagógica! Não à BNCC! Disponível em: http://www.anped.org.br/news/entidades-se-posicionam-contrarias-padronizacao-econtrole-impostos-pelo-programa-de-residencia. Acesso em: 11 out. 2019.
} 
inicial e continuada de professores da educação básica"10, divulgado em audiência pública no Conselho Nacional de Educação, no dia 8 de outubro de 2019 em Brasília, a Associação critica a adoção em políticas de formação docente recentes, vinculadas à aprendizagem das competências contempladas na BNCC, como mecanismo para efetivar a sua implementação na escola básica. Essa perspectiva sugere um perfil de professor próximo daquele "que executa do que aquele que toma decisões como um profissional da educação sobre o currículo da escola em que leciona" (ANPED, 2019, p. 13). Essa vinculação atenta contra a autonomia universitária, ao sugerir que as IES alterem seus projetos institucionais de formação e assumam concepções de formação docente destoantes do que preveem seus próprios projetos pedagógicos, o que também infligiria o recomendado nas DCN/2015.

Ressalta-se, ainda, que o Programa inclui, entre as "abordagens e ações obrigatórias" da Residência Pedagógica, "a apropriação analítica e crítica da BNCC nos seus princípios e fundamentos" e exige a elaboração de

atividades que envolvam as competências, os conteúdos das áreas e dos componentes, as unidades temáticas e os objetos de estudo previstos na BNCC, criando-se e executando-se sequências didáticas, planos de aula, avaliações e outras ações pedagógicas (CAPES/MEC, 2018).

Assim, na contramão de uma formação inicial na perspectiva de práxis, a proposta expressa uma concepção reducionista da formação docente, pautada pela desvinculação de teoria e prática, e restringe a formação de professores ao 'como fazer'. Essa perspectiva alinha-se aos interesses mercadológicos, com forte apelo ao conceito de competências, concepção que defende o exercício técnico-profissional, confere ao trabalho do

\footnotetext{
${ }^{10}$ Posição da ANPEd sobre texto referência - DCN e BNCC para formação inicial e continuada de Professores da Educação Básica. Disponível em: http://www.anped.org.br/news/posicao-da-anped-sobre-texto-referencia-den-ebncc-para-formacao-inicial-e-continuada-de. Acesso em: 12 out. 2019.
} 
professor um caráter de atividade artesanal, e restringe competências a um saber prático (VEIGA, 2002), o que reforça um modelo pré-determinado e padronizado de profissional.

Diante disso, é relevante compreender o que pensam sobre a docência professores de IES que formam os futuros docentes para a Educação Básica.

\section{A docência pensada por quem forma o professor}

A partir do reconhecimento da ação do professor como atividade humana objetiva e de que as concepções de quem forma o futuro professor implicam no tipo de transformação "prático-crítica" (MARX e ENGELS, 2007) nessa formação, buscou-se escutar professores que formam futuros docentes (Pedagogia, Educação Física e História) da Educação Básica, de uma IES pública por meio de entrevistas narrativas. O intuito é destacar os elementos que caracterizam a docência concebida por eles e os que se relacionam às concepções expressas nas DCN/2015 e no PRP/2018.

Os professores do curso de História e de Pedagogia são do quadro permanente do magistério público superior e o professor do curso de Educação Física é do quadro do magistério da Educação Básica e estava cedido à IES por força de um convênio com a Secretaria de Estado de Educação no período em que foi realizada a entrevista. Os professores têm experiência de docência na Educação Básica e desempenham atividades semelhantes; são afetados pelas mesmas condições de trabalho, material, salarial, de infraestrutura física e administrativa e de formação continuada.

O professor de Educação Física considera a docência numa "perspectiva individual e coletiva” que, conforme Nóvoa (1992, p. 25), "implica um investimento pessoal, um trabalho livre e criativo sobre os percursos e os projetos próprios, com vista à construção de uma identidade, que é também uma identidade profissional". A docência é um processo construído em uma trajetória de vida pessoal e profissional, o que nela se 
constrói repercute na constituição própria de cada sujeito, em sua forma de ser e estar no mundo e na profissão.

Ao mesmo tempo, a formação dá significado aos caminhos traçados pelo professor em sua trajetória de vida pessoal e profissional, considerando que "o professor é a pessoa e uma parte da pessoa é o professor" (NIAS apud NÓVOA, 1992, p. 25). Nesse processo, a formação inicial dos professores e as idiossincrasias intervêm na constituição e no trabalho docentes, mas, como já discutido, a qualidade desse trabalho depende de condições externas como as enunciadas anteriormente.

A outra perspectiva destacada pelo professor do curso de Educação Física é da docência como um processo de trabalho coletivo. Nesse caso, a docência é processo relacional em que "o homem, ser de relações e não só de contatos, não apenas está no mundo, mas com o mundo" (FREIRE, 1996, p. 47). Essa é a docência relacional, comprometida com a transformação individual e social, e que requer um modelo de formação crítica e articulada à realidade escolar, na direção do que propõem as DCN/2015.

O professor do curso de Pedagogia compreende a docência influenciada pela forma como se deu sua entrada na universidade pública ainda como estudante, momento em que manifesta que foi "tomando consciência de que é nesse espaço que se vai traçando o perfil profissional”. Para ele, as experiências formativas vivenciadas na licenciatura foram fundantes na sua constituição docente e repercutem na sua prática docente e na formação de futuros professores para a Educação Básica. O professor acrescenta que a docência é "uma atividade de relações e interações humanas que contribui para a formação de pessoas para atuarem com outras pessoas na construção de conhecimentos”. É um trabalho

com seres humanos, sobre seres humanos, para seres humanos, uma atividade em que o trabalhador se dedica ao seu 'objeto' de trabalho, que é justamente um outro ser humano, no modo fundamental da interação (TARDIF e LESSARD, 2002, p. 31). 
Essa compreensão da docência não prescinde dos conhecimentos científicos e pedagógicos necessários para o exercício de ensinar, mas se caracteriza fortemente pela dimensão humana, porque se concretiza a partir de uma relação fundamental, a relação professor-aluno em contextos diferenciados e complexos, como a sala de aula. Ela possibilita, conforme expressa o Professor da Pedagogia,

entender o outro na posição do outro, significa negar-se, superar o narcisismo pedagógico. Para ter o pleno desenvolvimento pedagógico, o professor precisa repensar o seu egocentrismo, porque, na sala de aula, é preciso entender 40 alunos.

É possível apreender que as concepções de docência apresentadas pelos professores de Educação Física e de Pedagogia se complementam e se diversificam na forma de compreendê-la como trabalho a partir do qual o professor se desenvolve e contribui para a formação de outros professores. São concepções de docência que requerem a integralidade de conhecimentos específicos de sua área de formação, pedagógicos e experienciais, o compromisso com as mudanças sociais e educacionais e as rupturas com a perspectiva do conhecimento científico definitivo e imutável, tratado de forma pragmática, como sugere o PRP/2018.

Para o professor de História, a docência "é sacerdócio. [...]. No binômio conhecimento de primeira mão e sacerdócio está o segredo da docência: tem que amar muito". Essa concepção apresenta uma aparente ambiguidade: a docência aliada à profissão, à pesquisa e à docência vocacional/sacerdotal. A concepção de docência como vocação e sacerdócio foi hegemônica do século XV até a metade do século XVIII, período de forte influência da Igreja na condução da educação, e decorre da necessidade de inserção de professores leigos como colaboradores na tarefa de ensinar, no contexto de urbanização decorrente do avanço das relações capitalistas que impuseram a ampliação da oferta escolar. De acordo com Hypólito (1999), para atuarem como professores, os leigos deveriam declarar uma fé e jurar fidelidade aos 
preceitos da Igreja. Embora essa ideia tenha se alterado ao longo dos anos, sua essência ainda permanece no imaginário social e dos professores e tem orientado políticas públicas de formação.

A docência como sacerdócio pressupõe o professor como alguém que atua por vocação e deveria ser uma pessoa repleta de virtudes com a disponibilidade integral ao ofício, à compreensão, ao amor e à benevolência, sendo atribuído ao docente um comportamento acima do comum, conforme analisa Nóvoa (1991). A secundarização de políticas educacionais voltadas à melhoria das condições de trabalho e de valorização dos professores corrobora a visão de docência sacerdotal, que exime o professor da luta pela profissionalidade docente.

Por outro lado, ao falar do "conhecimento de primeira mão", o professor de História se refere ao trabalho com fontes na aula como opção metodológica reforçada pelas suas experiências como estudante e por pesquisas direcionadas no sentido de não se restringir a leituras de comentadores: "A universidade só lê comentadores. Ficamos repetindo o que os outros acham e é isso o que todo mundo aqui faz". Essa perspectiva remete à busca de superação da docência conservadora e reprodutivista para a docência crítica que instrumentalize teórica e metodologicamente os futuros professores para análise crítica de sua prática social e das questões complexas que emergem no contexto da escola e da sala de aula, reconhecendo suas múltiplas determinações.

\section{Considerações finais}

A discussão neste artigo partiu do pressuposto de que os discursos e as políticas educacionais voltados à docência e à formação de professores resultam de orientações políticas, ideológicas e econômicas que embasam os arranjos de poder no atual contexto histórico brasileiro. Exemplo dessa influência é a dissonância entre o que prevêm as DCN/2015 e o PRP/2018. O 
primeiro documento foi elaborado de forma discutida e em outro contexto histórico e político e defende que a elaboração e o desenvolvimento do projeto de formação ocorram por meio da articulação entre a IES e o sistema de educação básica, com o objetivo de inserir os estudantes de licenciatura na escola, espaço privilegiado da práxis docente. O PRP foi instituído em fevereiro de 2018, ano eleitoral, portanto, em um contexto de incertezas quanto ao futuro político do Brasil e das políticas em implementação e, ao mesmo tempo, de contigenciamento de recursos financeiros para a educação pública.

A Portaria do PRP/2018 secundariza a prerrogativa das IES na elaboração coletiva de uma proposta que considere a prática como componente curricular nos projetos pedagógicos dos cursos em parceria com as escolas. Ela utiliza a formação como uma estratégia dos órgãos do Estado para promover alterações no estágio a partir de uma ideia transposta da área médica, vinculada aos interesses em garantir a 'adesão' das IES à política curricular da Educação Básica. Assim, ao mesmo tempo em que o discurso presente no documento do PRP reforça a centralidade da escola e da universidade na formação docente, oculta a intenção de desconstruir e desvalorizar projetos de formação inicial comprometidos com a docência como atividade criadora e intelectual.

As concepções expressas pelos professores de Educação Física e Pedagogia reiteram a docência como: um processo de trabalho coletivo; atividade de relações e interações humanas; a sua construção em uma trajetória profissional influenciada pela vida pessoal como interveniente na constituição docente. Por outro lado, a concepção do professor de História apresenta uma ambiguidade - docência aliada à profissão, à pesquisa e à atividade sacerdotal. Na docência como sacerdócio, o professor atua por vocação, desconsiderando que o trabalho docente compreende intencionalidades vinculadas às finalidades sociais e políticas da educação, e independe das condições objetivas materiais para desenvolvê-lo.

Como desfecho, se reconhece a distância entre o contexto de influência 
das políticas, do contexto de sua produção pelos governos e do contexto das práticas, ou seja, da concretude das políticas no espaço das IES e das escolas. Esses contextos são permeados por disputas em torno da política, em um cenário social e educacional de conflitos, contradições e interesses orientados por uma lógica com fortes demarcações mercadológicas e gerenciais.

Ressalta-se que a forma como a docência é tratada nos documentos analisados influencia a construção de discursos acerca da docência, da formação de professores e do ser docente. Esses podem se orientar por perspectivas teóricas conservadoras ou transformadoras e pelo reconhecimento da docência profissionalizada ou desprofissionalizada.

Estudos em andamento, ajudarão a analisar os impactos das orientações dos documentos discutidos na formação docente e na docência. Assim, as reflexões suscitadas neste artigo vão no sentido de contribuir para o debate necessário em um contexto de disputas e embates acerca da docência, do professor e de sua formação. A expectativa é avançar na construção de um projeto de formação de professores como compromisso social, que reconheça a docência como profissão complexa que requer formação crítica e emancipadora, desenvolvida em processos que articulem teoria e prática, ensino e pesquisa para atender aos desafios apresentados pela profissão.

\section{Referências}

ANPED. Posição da ANPEd sobre texto referência - DCN e BNCC para formação inicial e continuada de Professores da Educação Básica. Disponível em: $<\mathrm{http} / / /$ www.anped.org.br/news/posicao-da-anped-sobre-texto-referencia-den-ebnccpara-formacao-inicial-e-continuada-de>. Acesso em: 11 de out. 2019.

ANTUNES, R.; PINTO, G.A. A fábrica da educação: da especialização taylorista à flexibilidade toyotista. São Paulo: Cortez, 2017.

ARROYO, M. G. Ofício de mestre: imagens e autoimagens. Petrópolis: Vozes, 2000. 
BALL, S.J. Sociologia das políticas educacionais e pesquisa crítico-social: uma revisão das políticas educacionais e da pesquisa em políticas educacional. Currículo sem fronteira, v. $6, \quad \mathrm{n}^{\circ}$ 2, p. 10-32, jul./dez. 2006. Disponível em: www.curriculosemfronteiras.org. Acesso em: 23 jul. 2019.

BRASIL. Emenda Constitucional $n^{\circ}$ 95, de 15 de dezembro de 2016. Altera o Ato das Disposições Constitucionais Transitórias, para instituir o Novo Regime Fiscal e dá outras providências. Brasília: DF, 2016.

. Ministério da Educação. Resolução n. 2, de 01 de julho de 2015. Define as Diretrizes Curriculares Nacionais para a formação inicial em nível superior (cursos de licenciatura, cursos de formação pedagógica para graduados e cursos de segunda licenciatura) e para a formação continuada. Diário Oficial da União: seção 1, Brasília, DF, 2 jul. 2015. Disponível em: http://pronacampo.mec.gov.br/images/ pdf/res_cne_cp_02_03072015.pdf. Acesso em: 23 jul. 2019.

Política Nacional de Formação de Professores. Brasília: 2017 (slides apresentados por Maria Helena Guimarães de Castro). Disponível em $<$ http://portal.mec.gov.br/docman/outubro-2017-pdf/74041-formacao-professor-final18-10-17-pdf/file>. Acesso em: 05 out. 2019.

BRZEZINSKI, I. Profissão professor: identidade e profissionalização docente. Brasília: Plano Editora, 2002.

CIAVATTA, M; RAMOS, M. A "era das diretrizes": a disputa pelo projeto de educação dos mais pobres. In: Revista Brasileira de Educação, v. 17 n 49 jan.-abr. 2012, p. 11-38. Rio de Janeiro.

CURADO SILVA, K.A.P.C. Professores com formação stricto sensu e o desenvolvimento da pesquisa na educação básica da rede pública de Goiânia: realidades, entraves e possibilidades. 2008. Tese (Doutorado em Educação) - PPGE - UFG, Goiânia.

CURADO SILVA, K.A.P.C.; LIMONTA, S.V. Formação de professores em uma perspectiva crítico-emancipadora: a materialidade da utopia. In: CURADO SILVA, K.A.P.C.; LIMONTA, S.V. (Orgs.). Formação de professores na perspectiva crítica: resistência e utopia. Brasília: Editora Universidade de Brasília, 2014.

FAIRCLOUGH, N. Discurso e mudança social. Brasília: Universidade de Brasília, 2001.

Analysing discourse. Textual analysis for social research. London: Routledge, 2003.

FARIAS, I.M.S.de. O discurso curricular da proposta para a BNC da formação de professores da educação básica. Revista Retratos da Escola, Brasília, v. 13, n. 25, p. 155-168, jan./mai.2019. Disponível em: <http//www.esforce.org.br.

FREIRE, P. Pedagogia da autonomia: saberes necessários à prática educativa. São Paulo: Paz e Terra, 1996. 
GARCIA, C.M.:A Formação de Professores: Novas Perspectivas, baseadas na investigação sobre o pensamento do professor. In: NÓVOA, A. Os professores e sua formação. Lisboa: Dom Quixote, 1999.

HYPÓLITO, A.M. Trabalho docente e profissionalização: sonho prometido ou sonho negado? In: VEIGA, I.P.A e CUNHA, M.I.da. (Orgs.) Desmistificando a profissionalização do magistério. Campinas: Papirus, 1999.

INFOPÉDIA. Docência. In: Dicionário infopédia da Língua Portuguesa [em linha]. Porto: Porto Editora, 2003-2018. [consult. 2018-07-25 13:40:36]. Disponível em: https://www.infopedia.pt/dicionarios/lingua-portuguesa/docência. Acesso em: 25 jul. 18.

JÁEN, M.J. Os docentes e a racionalização do trabalho em educação: elementos para uma crítica da teoria da proletarização dos docentes. Teoria e Educação, Porto Alegre, $n^{\circ} 4$, p. 74-90, 1991.

MARX, K.; ENGELS, F. A ideologia alemã. São Paulo: Martins Fontes, 2007.

MEC/CAPES, 2018. Portaria $n^{\circ} 38$, de 28 de fevereiro de 2018. Institui o Programa de Residência Pedagógica. Brasília, DF. 2018.

NÓVOA, A. Para o estudo sócio-histórico da gênese e desenvolvimento da profissão docente. Teoria \& Educação, Porto Alegre, 1991.

Formação de professores e profissão docente. In: NÓVOA, A. Os professores e a sua formação. Lisboa: Publicações Dom Quixote - Instituto de Inovação Educacional, 1992.

SÁNCHEZ VÁZQUEZ, 2007, A. Filosofia da práxis. $2^{\mathrm{a}}$ ed. Rio de Janeiro: Paz e Terra, 2007.

SAVIANI, D. Pedagogia histórico-crítica: primeiras aproximações. São Paulo: Cortez \& Associados, 1991.

Formação de professores no Brasil: dilemas e perspectivas. In: Poíesis Pedagógica - V. 9, N. 1 jan/jun. 2011, pp. 07-19.

SCHÜTZ, A. El problema de la realidad social. Buenos Aires: Amorrortu, 1974.

SILVA, K.A.C.P.C.da; CRUZ, S.P.S. Formação e atuação de professores: perspectivas e trajetos de pesquisas. In: SILVA, K.A.C.P.C.da; CRUZ, S.P.S; CASSETARI, N.; ROCHA, D.R. Formação de professores: concepções e políticas. Jundiaí, SP: Paco, 2017.

SILVA, K.A.C.P.C.da. Epistemologia da práxis na formação de professores: perspectiva crítico-emancipadora. Campinas, SP: Mercado das Letras, 2018. 
TARDIF, Maurice. Saberes docentes e formação profissional. Petrópolis: Vozes, 2002.

THOMPSON, J.B. Ideologia e cultura moderna. Petrópolis: Vozes, 1995.

VEIGA, I.P.A. Caminhos da profissionalização do magistério. Campinas: Papirus, 1998.

VEIGA, I.P.A; AMARAL, A.L. (orgs.). Professor: Tecnólogo do ensino ou agente social? In: Formação de professores: políticas e debates. Campinas, SP: Papirus, 2002.

.A aventura de formar professores. Campinas, SP: Papirus, 2009.

Professor: Tecnólogo do ensino ou agente social? In: VEIGA, I.P.A.; AMARAL, A.L. (orgs.). Formação de professores: políticas e debates. Campinas, SP: Papirus, 2002.

ZABALZA, M. A.; CERDEIRIÑA, M.A.Z. Formação e docência na educação básica e superior: novos tempos, novos rumos. In: VEIGA, I.P.A; VIANA, C.M.A.Q.; SILVA, E.F; MACHADO, L.C. (orgs.). Docência, currículo e avaliação: territórios referenciais para a formação docente. Curitiba: CRV, 2017.

Recebido em agosto de 2019. Aprovado em novembro de 2019. 